\title{
Bringing Out the Best in People: a Psychological Perspective
}

David Orr's (2008) call for a greater role for psychology in efforts to ensure "a decent future" for humanity is right on. Psychology has much to offer to the understanding of and approaches to survival and sustainability. Furthermore, Orr is correct that people in the field should have made psychology's potential contribution more visible. Unfortunately, despite the strong efforts of the Society for Conservation Biology's Social Science Working Group, the psychological sciences are less evident than other social sciences. Psychology has been far too slow to identify opportunities where its perspective could have important impacts on conservation.

There are many ways to consider psychology's potential contribution. Although Orr casts these in terms of the study of "mind," we have found it more effective to talk about "human functioning" and specifically to consider what brings out the best in people. Many of Orr's examples point to the opposite-situations (e.g., Milgram study) that have brought out undesirable qualities in people. Although situations are important influences, it is by no means the case that their outcomes are uniformly (or even predominantly) negative. Rather, there is a wide range of situations that can bring out the best in people. This is a particularly critical issue when one thinks about endangered environments. Natural environments, for example, have been repeatedly shown to have the capacity to bring out the best in people even when nature is no more than the view of a tree from a window (Kaplan 1993; Frumkin 2001; Kaplan \& Kaplan 2005).

As for an emphasis on human selfishness and self-interest, this too provides only a partial view of our species. It is true that advertising and the media have adeptly orchestrated a materialistic culture in which consumption has become an escapist distraction relative to the values that are essential for a sustainable world. Here, perhaps, neoclassical economics helps explain behavior. The behavioral economists, however, have identified a broad range of circumstances in which people do not maximize their personal gain, but rather are cooperative and reasonable (Hammerstein \& Hagen 2005). For example, research on how people deal with antisocial behavior shows that punishing violators is experienced as pleasurable even when it costs in terms of one's material standing (Angier 2002). The vast body of research on human well-being has identified many dimensions of this complex domain, including hedonic pleasure, emotional well-being, psychological capital, and character strengths (e.g., Ring et al. 2007; Kesebir \& Diener 2008; Ryff \& Singer 2008). Particularly pertinent to the discussion here is that many human qualities are inconsistently exhibited within the same person across time and circumstances. In other words, the dimensions of well-being or of what people find satisfying are not immutable; rather, they are strongly influenced by context or situation (Luthans et al. 2007).

From our perspective this is central to the issue of what brings out the best in people. In our experience psychology can provide a better understanding of the contexts, or environments, that are more likely to achieve survival and sustainability. Such outcomes, however, are not necessarily or primarily concerned with individual well-being. Maximizing individual well-being can, and often has, come at a great cost; vast global inequities are an iconic expression. Rather, we see that a more benign and more effective route to well-being involves maximizing the larger social good. The agenda must be to foster reasonableness (e.g., being responsible, cooperative, and tolerant). There is reason to believe that a great deal of human satisfaction and well-being flows from participation in actions that improve the lives of others.

The reasonable person model (RPM) is a framework we have been developing for understanding these bringing-out-the-best-in-people contexts (Kaplan \& Kaplan 2003; R. and S. Kaplan, unpublished data). These contexts are ones that help meet basic human needs, and the needs are conceptualized in terms of one of the most pervasive characteristic of the species-concern about and dependence on information. Information is what we store, trade, hide, and act on. We are overwhelmed by it, yet endlessly seek it. We cannot act without it. 
The RPM organizes human informational needs into three major categories. These are highly interconnected and often interdependent, yet they address different domains that are all important for fostering reasonableness. These needs relate to understanding what is going on around one (building models), the capacity to utilize knowledge and skill (being effective), and the desire to be needed and to make a difference (meaningful action).

\section{Building Models}

By models we mean mental models, the basic structures of the mind that store knowledge and its affective qualities. Craik (1943:61) summarizes the essential qualities of these models eloquently:

If the organism carries a "smallscale model" of external reality and of its own possible actions within its head, it is able to try out various alternatives, conclude which is the best of them, react to future situations before they arise, utilize the knowledge of past events in dealing with the present and future, and in every way to react in a much fuller, easier, and more competent manner to the emergencies which face it.

Building these models is a lifelong enterprise. The psychology of survival is intimately related to appreciation of the complexities of this building program. There are no kits for these models or easy mechanisms for transporting them from one head to another. A vast body of psychological research tells us that the mental models develop with experience. In other words, not only is understanding achieved with repeated exposure to aspects of the model's domain, but exploration of the domain is more effective than others' efforts to deliver the model (Bransford et al. 2000).

In our view, at the core of the public's inertia about daunting global events is the lack of adequate mental models. People are constantly bombarded with conflicting information about climate change, biodiversity, and other major environmental issues. Much of the information is provided with technical details and little imagery about ways to explore the pertinent domains. People dislike feeling confused and overwhelmed; when information is not meaningful, it is likely to be ignored.

Similarly, efforts to persuade people to change their attitudes are also often unlikely to be fruitful because the messages fail to connect with the mental models of the intended recipients. There is considerable evidence that people deeply resent being told what to do (Brehm 1966); it is not only teenagers who may decide under such circumstances to do the opposite of what they are told! Thus, a more appropriate alternative is to view the process as one of helping a fellow human build a model. This model must make sense relative to the experience the individual already has. This suggests the importance of listening (an activity that is readily neglected among those eager to insert their ideas and beliefs in the minds of others). The desired attitude change is also more likely to take shape if the recipient is given a chance to explore options and to take small steps in the desired direction.

\section{Being Effective}

People also dislike feeling incompetent. Being overwhelmed by information, and especially information that is confusing, seemingly urgent, and largely uninterpretable, is unlikely to contribute to clearheadedness or a sense of competence. It is hardly surprising that people in such situations can become unpleasant, uncooperative, and even destructive. Being civil is difficult when the mind is noisy with confusion and despair. Thus, being an information-based species comes with the necessity to cope with managing information.

It is useful to distinguish between 2 dimensions of information in understanding how to manage our dependence on it while also coping with its (over)abundance. The distinction is derived from the kinds of attention needed to process information. Much of the time the information surrounding people requires their attention; one needs to listen to a lecture or an endless conversation, to read something intently to use it in a document, or to simultaneously attend to different demands. Such information takes focus and effort and is referred to as directed attention. A person can maintain or direct attention for only so long before becoming less effective (i.e., before attention capacity declines). People recognize this condition as being tired or stressed out. Interestingly, however, fatigue is differential. People are not too tired to resume reading a novel, to solve a crossword puzzle, or to go on a walk and take pictures of trees in bloom. Such tasks also require processing information, but the information is inherently fascinating and thus is effortless.

Attention restoration theory (ART; Kaplan \& Kaplan 1989/1995; Kaplan 1995) contends that attention plays a key role in why mental fatigue occurs and in how restorative environments can foster recovery. Mental fatigue is the result of declining capacity to use directed attention. Recovering from it calls on the other kind of attention, attention to activities that are fascinating and compelling. Attention restoration theory posits that time spent in such effortless pursuits and contexts is an important factor in the recovery from mental fatigue. In other words, restoration involves activities and settings that are compelling and allow directed attention to rest. Tending to our attentional needs is central for achieving clearheadedness. There is a substantial empirical literature, drawing on ART, that documents the important role the natural environment can play 
in recovering attentional capacities (Tennessen \& Cimprich 1995; Kuo \& Sullivan 2001; Cimprich \& Ronis 2003; Berto 2005).

\section{Meaningful Action}

News about catastrophes and calamities, war and terror, and abuse and corruption foster a sense of hopelessness and helplessness. In their despair about chaos and tragedy, people often reach out to try to salvage something small and graspable. There are many examples of when substantial amounts of money are contributed to help an individual who survived a disaster when hundreds of others may have perished. People have a need to find meaning and to act in ways that enhance that meaningfulness. The acts may be small or big, lasting a moment (e.g., voting) or lasting a long time. They may involve people one knows well or strangers; they may be directed to other people or to many other outcomes. For example, volunteers involved in environmental stewardship believe they are improving the environment and contributing to a better world (Grese et al. 2000). Such actions give one a sense that one can make a difference, that one participates in a larger whole.

Hopefulness abounds in the cornucopia of examples and stories of people's actions to address the array of contemporary woes. Bornstein's (2004) book offers stunning examples of individuals who have made a difference in ways that have multiplied many times over as their efforts have found replication. Hawken's (2007) Blessed Unrest bears a subtitle that speaks directly to these issues: How the Largest Movement in the World Came into Being and Why No One Saw It Coming. That movement is the groundswell of meaningful action, the thousands of organizations that have sprung up around the world to address aspects of these woes. The Web site behind this effort (www.wiserearth.org) invites viewers to explore " 108,705 organizations, 12,621 people, 526 groups, 353 events, and 143 jobs." The areas of focus are organized under several dozen major headings (e.g., agriculture and farming, biodiversity, coastal and marine ecosystems, community development, and energy) with numerous subheadings for each. It is an impressive anthology of positive examples and of the human inclination to act meaningfully.

We know of no empirical evidence, but one would suspect that those who are deeply involved in these organizations and activities are likely to feel less helpless about the state of the world. Still, even when one has experience with what to do, it may not be sufficient to counter the sinking feeling that it cannot possibly be enough, that no matter the size of the effort, the negative forces are too strong and coming too fast to be stopped by individuals' actions. But what if the media have been falling down on the job? What if they have been failing to tell us how many exciting, ingenious, and well-financed projects are already under way and that their potential is huge? This is precisely the message of Krupp and Horn's (2008) book, Earth, the Sequel. They provide an eminently readable survey of the multiplicity of innovative projects involving 6 different forms of energy. Although the frustration the book evokes concerning the failure of the media is warranted, the hopefulness it fosters leads one to believe that the cumulative effects of individual efforts may well matter. Krupp and Horn provide a basis for believing that the whole is far greater than the sum of the parts. Together, if everyone does their part, humanity and the ecosystems it depends on may have a good chance of survival after all.

Although discussed in the context of meaningful action, the examples we provide here also illustrate the vital roles of model building and being effective. The 3 domains of RPM are interdependent. Active involvement in an organization calls on exploration and fosters greater understanding, which can enhance one's sense of competence and inspire sustained engagement in an activity.

\section{Rachel Kaplan* and Stephen Kaplan $†$}

${ }^{*}$ School of Natural Resources and Environment, University of Michigan, 3516 Dana Building, Ann Arbor, MI 48109-1041, U.S.A., email rkaplan@umich.edu

†Department of Psychology and Department of Computer Science and Engineering, University of Michigan, 530 Church Street, Ann Arbor, MI 48109-1043, U.S.A.

\section{Literature Cited}

Angier, N. 2002. Why we're so nice: we're wired to cooperate. New York Times, 23 July. Available from http://www.nytimes. com/2002/07/23/health/psychology/23 COOP.html?ex =1028431942\&ei=1\&en= f6ad671e3dcf7d16 (accessed May 2008).

Berto, R. 2005. Exposure to restorative environments helps restore attentional capacity. Journal of Environmental Psychology 25:249-259.

Bornstein, D. 2004. How to change the world: social entrepreneurs and the power of new ideas. Oxford University Press, New York.

Bransford, J. D., A. L. Brown, and R. R. Cocking. 2000. How people learn: brain, mind, experience, and school. National Academy Press, Washington, D.C.

Brehm, J. W. 1966. A theory of psychological reactance. Academic Press, New York.

Cimprich, B., and D. L. Ronis. 2003. An environmental intervention to restore attention in women with newly diagnosed breast cancer. Cancer Nursing 16:83-92.

Craik, K. J. W. 1943. The nature of explanation. Cambridge University Press, London.

Frumkin, H. 2001. Beyond toxicity: human health and the natural environment. American Journal of Preventive Medicine 20:234-242.

Grese, R. E., R. Kaplan, R. L. Ryan, and J. Buxton. 2000. Psychological benefits of volunteering in stewardship programs. Pages 265-280 in P. H. Gobster and R. B. Hull, editors. Restoring nature: perspectives from the social sciences and humanities. Island Press, Washington, D.C.

Hammerstein, P., and E. H. Hagen. 2005. The second wave of evolutionary economics in biology. Trends in Ecology \& Evolution 20:604-609.

Hawken, P. 2007. Blessed unrest: how the largest movement in the world came into being, and why no one saw it coming. Viking, New York. 
Kaplan, R. 1993. The role of nature in the context of the workplace. Landscape and Urban Planning 26:193-201.

Kaplan, R., and S. Kaplan. 1989/1995. The experience of nature: a psychological perspective. Cambridge University Press, New York. Republished by Ulrich's, Ann Arbor, Michigan.

Kaplan, R., and S. Kaplan. 2005. Preference, restoration, and meaningful action in the context of nearby nature. Pages 271-298 in P. F. Barlett, editor. Urban place: reconnecting with the natural world. The MIT Press, Cambridge, Massachusetts.

Kaplan, S. 1995. The restorative benefits of nature: toward an integrative frame work. Journal of Environmental Psychology 15:169-182.
Kaplan, S., and R. Kaplan. 2003. Health, supportive environments, and the reasonable person model. American Journal of Public Health 93:1484-1489.

Kesebir, P., and E. Diener. 2008. In pursuit of happiness: empirical answers to philosophical questions. Perspectives on Psychological Science 3:117-125.

Krupp, F., and M. Horn. 2008. Earth, the sequel: the race to reinvent energy and stop global warming. Norton, New York.

Kuo, F. E., and W. C. Sullivan. 2001. Aggression and violence in the inner city: impacts of environment via mental fatigue. Environment and Behavior 33:53-57.

Luthans, F., B. J. Avolio, J. B. Avey, and S. M. Norman. 2007. Positive psychological capital: measurement and relationship with performance and satisfaction. Personnel Psychology 60:541-572.

Orr, D. W. 2008. The psychology of survival. Conservation Biology 22: in press. [this issue].

Ring, L., S. Höfer, H. McGee, A. Hickey, and C. A. O'Boyle. 2007. Individual quality of life: can it be accounted for by psychological or subjective well-being? Social Indicators Research 82:443-461.

Ryff, C. D., and B. H. Singer. 2008. Know thyself and become what you are: a eudaimonic approach to psychological wellbeing. Journal of Happiness Studies 9:1339.

Tennessen, C. M., and B. Cimprich. 1995. Views to nature: effects on attention. Journal of Environmental Psychology 15:7785.

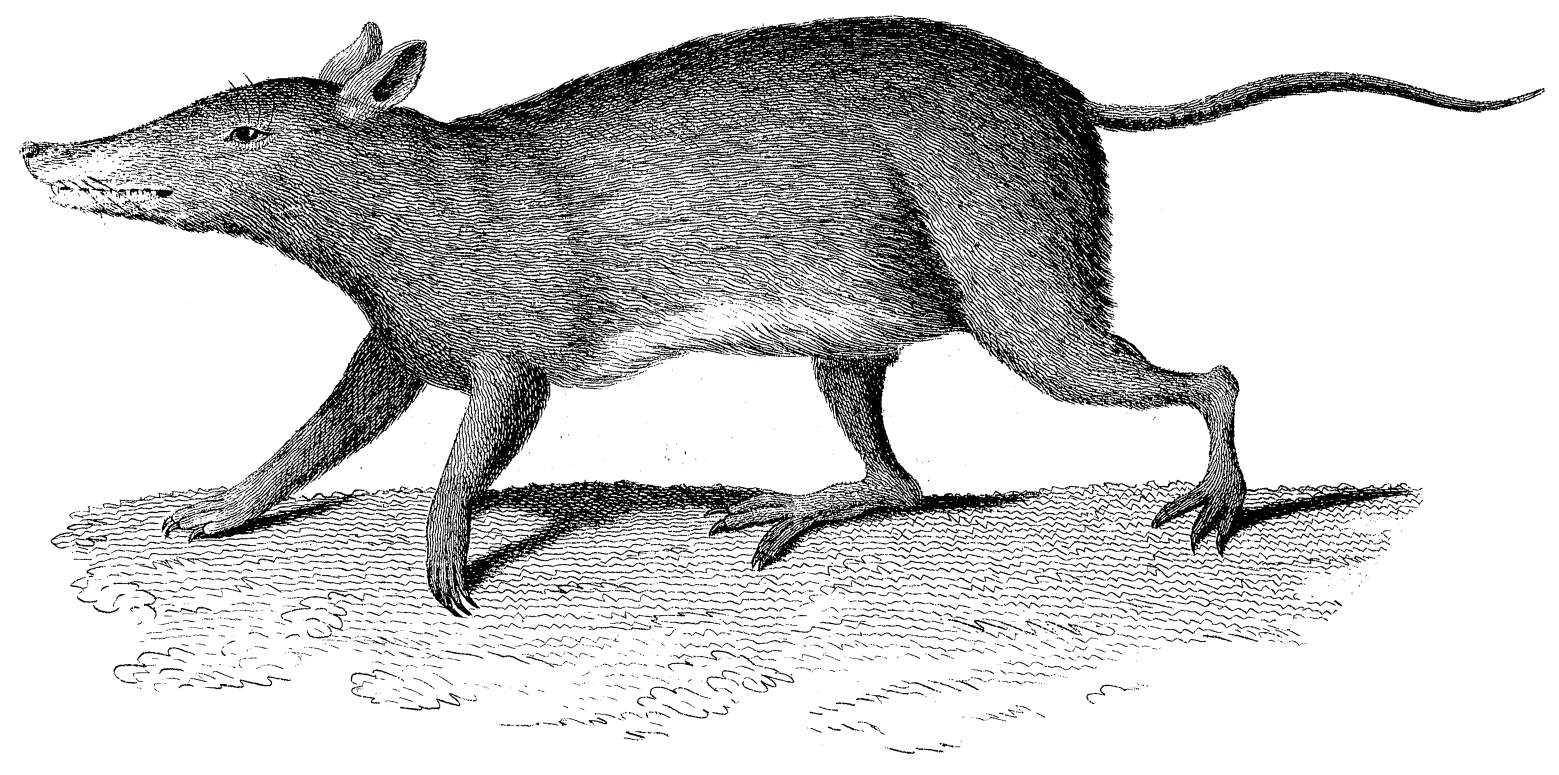

